\title{
Understanding dogwhistles politics
}

\author{
(Comprender la politica de los silbatos para perros)
}

\author{
José Ramón TORICES* \\ Universidad de Granada
}

\begin{abstract}
This paper aims to deepen our understanding of so-called covert dogwhistles. I discuss whether a covert dogwhistle is a specific sort of mechanism of manipulation or whether, on the contrary, it draws on other already familiar linguistic mechanisms such as implicatures or presuppositions. I put forward a series of arguments aimed at illustrating that implicatures and presuppositions, on the one hand, and covert dogwhistles, on the other, differ in their linguistic behaviour concerning plausible deniability, cancellability, calculability and mutual acceptance. I concluded this paper by outlining a simple theory for covert dogwhistles according to which they are attitude-foregrounders.
\end{abstract}

KEYWORDS: dogwhistles; implicatures; pressupositions; political manipulation.

RESUMEN: El objetivo de este artículo es profundizar en la comprensión de los llamados silbatos para perros encubiertos. A lo largo del mismo examino si un silbato para perros encubierto es un tipo de mecanismo especifico de manipulación o si, por el contrario, recurre a otros mecanismos lingüisticos ya conocidos, como son las implicaturas o las presuposiciones, para conseguir su objetivo. Para ello presento un conjunto de argumentos concebidos para ilustrar que las implicaturas y las presuposiciones, por un lado, y los silbatos para perros encubiertos, por otro, difieren en su comportamiento lingüistico en lo que respecta a la negación plausible, la cancelabilidad, la calculabilidad y la aceptación mutua. Concluyo este artículo esbozando una teoría simple para los silbatos para perros encubiertos según la cual estos son subrayadores de actitudes.

PALABRAS CLAVE: silbatos para perros; implicaturas, presuposiciones; manipulación política.

* Correspondence to: José Ramón Torices. Departamento de Filosofía I, Facultad de Psicología, Universidad de Granada, Campus Universitario de Cartuja, s/n (18011, Granada-Spain) - jrtorices@gmail.com - https://orcid.org/0000-0003-4078-1262

How to cite: Torices, José Ramón (2021). «Understanding dogwhistles politics»; Theoria. An International Journal for Theory, History and Foundations of Science, 36(3), 321-339. (https://doi.org/10.1387/theoria.22510).

Received: 2021-01-29; Final version: 2021-05-19.

ISSN 0495-4548 - eISSN 2171-679X / (c) 2021 UPV/EHU

c) (i) $\odot$ This work is licensed under a

Creative Commons Attribution-NonCommercial-NoDerivatives 4.0 International License 


\section{Introduction}

In societies where certain social norms of tolerance, justice and social equality are widely accepted, there is a cost to conspicuously skipping them. That is why those who want to bypass those norms without raising suspicion engage in dogwhistle politics by using linguistic and non-linguistic mechanisms that allow them to keep up appearances in the face of public opinion (Mendelberg, 2001; Albertson, 2015; Stanley, 2015; Khoo, 2017; Saul, 2018; Medina, 2018; Henderson \& McCready, 2019; Quaranto \& Stanley, 2021). For instance, some American politicians at times employ religious expressions in their speeches - not recognized as such by the entire audience - to draw the attention of the most faithful voters. But the purpose of this tactic is not just to attract the votes of the more fervent religious electorate. It is also about exhibiting the speaker's support of the interests of such constituents in a way that does not exclude voters of other religions, non-religious voters and even moderate voters of the same faith, all of whom may be reluctant to vote for a political leader who boasts about their religiosity by seeking the allegiance of the more radical religious sectors. Roughly speaking, dogwhistle politics is a communication strategy aimed at appealing to one part of the electorate without repelling another part of it whose support is also sought.

George W. Bush's speech in the 2003 State of the Union is an example of this strategy (see e.g., Albertson, 2015; Saul, 2018; Henderson \& McCready, 2019). About halfway through the speech, President W. Bush stated:

For so many in our country, the homeless, and the fatherless, the addicted-the need is great. Yet there is power-wonder-working power-in the goodness, and idealism, and faith of the American people. ${ }^{1}$

For many listeners, the phrase "wonder-working power" means nothing, not so for evangelists familiar with the hymn There is Power in the Blood. By using such religious appeal, George W. Bush earns or keeps the loyalty of one part of the audience without alienating the other. Bush's speechwriters, thus, devised inclusive communication techniques to persuade a diverse electorate whose ideologies might even be exclusive of one another. As Albertson (2015) shows, explicit or implicit religious messages are persuasive to members of the speaker's in-group. For members of the out-group, in contrast, explicit messages are not at all persuasive, but implicit messages are as persuasive as an analogous discourse without any religious reference.

Note, however, that dogwhistle politics is not a monolithic phenomenon. On the contrary, "dogwhistles politics" refers to a set of political manipulation mechanisms that share the same purpose but differ significantly in the way they achieve it. As we shall see, and following Saul (2018), the label applies to at least two different but closely related mechanisms of manipulation: overt and covert dogwhistles. The latter have received less attention in the otherwise limited philosophical literature on the matter, and many of the things that have been said about dogwhistles, in general, do not apply directly to them. Partly specialized literature and most media usually take it for granted that dogwhistles are code words with a kind of private meaning accessible for a subset of the audience only. A quick search on the Internet

1 Transcript of Bush's speech in The New York Times, JAN. 29, 2003. https://www.nytimes. com/2003/01/29/us/state-union-president-s-state-union-message-congress-nation.html 
proves this. However, as I will show throughout this paper, this is far from being the right way to explain how covert dogwhistles work. In what follows, I will argue that covert dogwhistles are neither a variety of implicatures nor presuppositions, two categories that are prima facie suitable for clarifying how some expressions have the potential to convey a coded meaning. I put forward a series of arguments aimed at illustrating that implicatures and presuppositions, on the one hand, and covert dogwhistles, on the other, differ in their linguistic behavior.

Section 2 is devoted to introducing the phenomenon of dogwhistling in politics, following Saul's aforementioned distinction between overt and covert dogwhistles. I contribute to Saul's taxonomy by introducing the different types of audiences that can come into play when a speaker engages in dogwhistle politics. Section 3 provides a case study for this paper. In section 4, I compare the linguistic behavior of implicatures, presuppositions and covert dogwhistles. Conventional implicatures and semantic presuppositions are not plausibly deniable, while covert dogwhistles are (4.1). Conversational implicatures are cancellable, calculable and plausibly deniable although at the cost of the speaker being perceived as uncooperative. In contrast, covert dogwhistles are neither cancellable nor calculable and are plausibly deniable without the speaker having to pay the price of being perceived as uncooperative (4.2). Finally, covert dogwhistles, unlike pragmatic presuppositions, do not require mutual acceptance of its content among speaker and listener to be successful (4.3). In section 5, I put forward two simple theories, Khoo's theory according to which dogwhistles are inference-triggers and my own proposal, based on Saul (2018), according to which covert dogwhistles are attitude-foregrounders. I argue briefly why the latter is better than the former. Section 6 takes stock of the phenomena discussed and draw some conclusions.

\section{Varieties of dogwhistles}

Dogwhistles are one of the many forms that propaganda can adopt. As presented above, one could hastily conclude that a dogwhistle is a speech act that necessarily relies on the speaker and (target) listeners mutual recognition of intentions. However, the speaker's intention and, what is more important, the audience's recognition of those intentions are not necessary for a speech act to be propagandistic, nor, indeed, for it to be a dogwhistle. On the contrary, as in other well-known cases of propaganda, sometimes its success depends precisely on going unnoticed by the (target) audience (see e.g., Ellul, 1965, p. 27). Thus, dogwhistles can be intentional or unintentional depending on whether the speaker carries out the dogwhistle deliberately or not and can also be overt or covert by virtue of whether the target audience is aware that a dogwhistle has been issued (see Saul 2018). Saul's distinction between overt and covert dogwhistles is a distinction between types of dogwhistles. Both types involve the concealment of information but differ in whether the concealment concerns the target audience.

Overt dogwhistles: dog-whistlers send a message to an audience with at least two possible interpretations where one of them, "often taboo, controversial or inflammatory" as Henderson and McCready (2019, p. 223) point out, is coded and recognized only by the target audience.

Covert dogwhistles: dog-whistlers use certain expressions that evoke (taboo, controversial or inflammatory) pre-existing attitudes in the audience without the audience being aware of it. 
Dogwhistles are aimed at an audience that is heterogeneous in its background. ${ }^{2}$ The dog-whistler thus exploits all this diverse background when dog-whistling (see Witten, 2014; Khoo, 2017). Witten (2014) introduces the distinction between general audience and target audience to capture how the speaker takes advantage of the different distribution of background among the members of the audience. This distinction is crucial, but it does not exhaust the full range of audiences involved in dogwhistles. So more distinctions are needed. It is also significant to make such distinctions bearing in mind the different types of dogwhistles mentioned above, as this will allow us to know better how they differ.

Overt dogwhistles involve two different audiences: the target audience, a subset of the general audience formed by those on whom the dogwhistle is expected to have some effect; and (what I call) the non-targeted audience, that is, that part of the audience for which the dogwhistle is intended to be ineffective. ${ }^{3}$ Thus, the target audience is made up of people who openly support the ideology to which the speaker appeals, i.e., the members of the speaker's ingroup. The non-targeted audience, on the other hand, is made up of (what I call) the oblivious audience: those who ignore the existence of the coded message ${ }^{4}$; and the mindful audience: those who are aware of the coded message even though they are not the intended recipients. The former is the manipulated audience, while the latter is the audience that detects the manipulation and can publicly denounce it. Let's think about the case introduced in section 1. Bush's phrase "wonder-working power", which is an overt dogwhistle, is heard by the general audience. The appeal to "the power of God," that is, the religious reference, is heard by the target audience and by the mindful non-targeted audience. ${ }^{5}$ The oblivious audience is the one who is deaf to the religious pitch.

For covert dogwhistles, things work slightly differently. There is no difference between the intended target and non-targeted audiences. And the target audience, which in principle could be the whole (general) audience, is oblivious to the fact that it is being targeted. Given the variety of perspectives encompassed in the target audience, it is possible to distinguish between a) those who become aware of the covert dogwhistle, albeit not necessar-

2 The background includes not only beliefs but also prejudices, stereotypes, idiolects, implicit biases and so on.

3 Note that target and non-targeted audiences do not necessarily match with the audiences in which the dogwhistle is in fact effective and not.

4 Overt dogwhistles are not necessarily about sending veiled messages. Sometimes it seems that they only serve for the speaker to attract the target audience's support by showing her ideological stance through the use of a specific identity language (see Saul, 2018, pp. 362-363). Henderson and McCready (2020, p. 155)'s identifying/enriching dogwhistles distinction is suitable for capturing this dual function of overt dogwhistles. Both identifying and enriching dogwhistles seem to involve recognition by listeners, recognition of the "speaker's persona/ideology", which make them overt according to Saul's taxonomy. According to Henderson and McCready, on the one hand, by means of an overt dogwhistle the speaker can simply communicate her ideological stance without that being materialized in a message with a concrete content (identifying dogwhistles). On the other hand, the speaker can, besides signalling her ideology, convey a message with a dual content: a conventional one, followed by the general audience, and a specific one only aimed at her in-group (enriching dogwhistles).

5 The non-targeted audience may not have mindful members. So, the dogwhistle may only be heard by the target audience. When this happens, the dogwhistle is absolutely successful. 
ily immediately (mindful audience ${ }^{6}$ ), and b) those who ignore the existence of the covert appeal (oblivious audience). Among those who belong to the oblivious audience are those in whom the dogwhistle is effective and those in whom it is not.

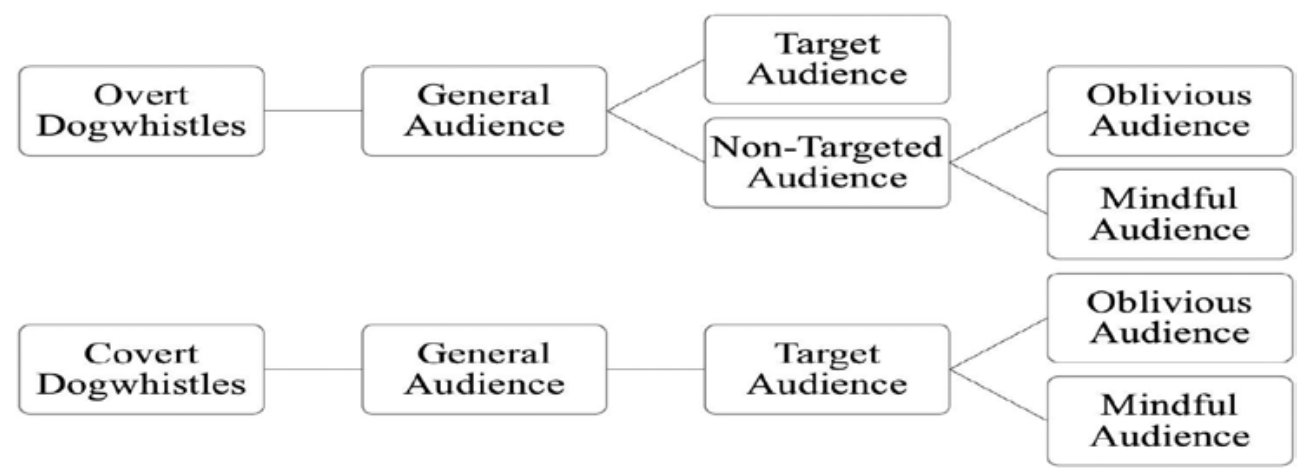

Figure 1

Varietes of Audiences involved in Dogwhistles

Having enriched Saul's taxonomy by introducing different types of audiences, namely by distinguishing both the oblivious and the mindful audience, we can think of Saul's distinction between overt and covert dogwhistles differently. It is now easy to see that the same dogwhistle can be simultaneously overt and covert for different subsets of the audience. In particular, a covert dogwhistle can be overt for the mindful audience. The philosophical challenge that will concern us in the remainder of this paper is thus to explain how covert dogwhistles work among the members of the oblivious audience in which they are successful. Before carrying out this task, I introduce a case study in the following section.

\section{Covert Dogwhistles: Newt Gingrich and "the Food Stamp President"}

Newt Gingrich, one of the candidates for the Republican Party's 2012 presidential nomination, was accused of using racially tinged language in labelling President Obama "the most successful food stamp president in American history". This is an extract of one of his speeches during the campaign:

6 In covert dogwhistles, the mindful audience can include both members of the speaker's in-group and members of the speaker's out-group.

7 Several media outlets echoed the racial tinge of Gingrich's statements. For instance, Juan Williams for Fox News https://www.youtube.com/watch?v=hs6fIPgLX0Y, Matthew C. Nisbet for Big Think https://bigthink.com/age-of-engagement/food-stamp-president-the-science-of-why-gingrichs-racetinged-label-sticks, Debbie Elliot for NPR https://www.npr.org/2012/01/17/145312069/newtsfood-stamp-president-racial-or-just-politics, and Al Sharpton for the MSNBC https://www.youtube. com $/$ watch? $=$ m_ulf $7 \mathrm{msl} \operatorname{Lg} \& \mathrm{t}=84 \mathrm{~s}$ 
Over here you have a policy which, with Reagan and me as speaker, created millions of jobsit's called paychecks. Over [ $t]$ here you have the most successful food stamp president in American history, Barack Obama. (Newt Gingrich, as cited in Elliott, 2012)

On the surface, Gingrich, as Reagan did before through the infamous "welfare queen" (see e.g., Haney-López, 2014; Stanley, 2015), was only voicing opposition to specific redistribution programs that, in his view, do not really help the most disadvantaged, but only serve to encourage laziness and perpetuate their dependent position while allowing free riders to take advantage of the good faith of taxpayers. However, even though no explicit mention to race is made, Gingrich was primary targeting African American on food stamps. As Haney-López points out, "like Reagan and Fedele and countless others, he [Gingrich] used references to food stamps to push the poison of race into the public's veins" (Haney-López, 2014, p. 131). Expressions like "food stamp", "inner city" or "welfare" are not expressions belonging to the idiolect of a part of the audience, as sometimes happens in overt dogwhistles. They are expressions used by the whole community of speakers of a given language. However, there are expressions, including those mentioned as evidenced empirically by several authors, that work effectively surreptitiously harnessing the racist attitudes of part of the electorate (see e.g., Gilens, 1996; Mendelberg, 2001; Valentino et al., 2002; Hurwitz \& Peffley, 2005; White, 2007). The associations between "food stamps" or "welfare" and "African Americans" root in racial stereotypes treating African American as lazy (Stanley, 2015, p. 156). Stereotypes, but also prejudices and implicit biases, are crucial in accounting for the effect that these expressions have on a part of the audience. Covert dogwhistles do not send veiled messages, but rather "raise subject's pre-existing attitudes to salience", making part of the audience act accordingly without realizing their influence (Saul, 2018, p. 367). It must be emphasized that the audience's unawareness that a speech act is bringing to the forefront their pre-existing racial attitudes is crucial to making the covert dogwhistle effective. As Mendelberg (2001, p. 210) shows in her analysis of Willie Horton's $\mathrm{ad}$, once the racist nature of the speech act or the ad is raised, audience attitudes begin to change again. ${ }^{8}$

According to Mendelberg (2001, p. 7), what leads dog-whistlers to omit a straightforward reference to the issue of race is "to avoid violating the norm of racial equality."

8 In the 1988 presidential election, Republicans launched an active campaign to favour their candidate George H. W. Bush and attack his opponent, Democrat Michael Dukakis. One of the issues that received the most attention in that campaign was that of crime. Republican-related groups released an ad praising Bush's firm stance on combating crime and criticizing Dukakis' weakness in the face of it since he opposed the death penalty and supported the granting of weekend passes. The ad briefly tells the story of Willie Horton, a black man sentenced to life imprisonment for murder, who, in one of those furloughs, "fled, kidnapping a young couple, stabbing the man and repeatedly raping his girlfriend". There was no mention of Horton being black during the ad. However, his image appeared along with words such as "kidnapping," "stabbing," and "rape". As Mendelberg (2001, pp. 3-4) points out, during the primary period, Dukakis was in the polls ahead of Bush. This trend began to change when Bush first mentioned the Horton story in June 1988. The most significant advantage in Bush's polls over Dukakis came in October when the campaign focused vehemently on the Horton case. After the racial nature of Horton's ad became explicit, the voting trend began to change somewhat, though not enough for Dukakis to end up winning the presidential election (See Mendelberg, 2001 for a highly detailed analysis of the case). 
This norm translates into the public rejection of blatant discrimination. However, as Saul (2018, p. 364) stresses, this widespread assumption does not necessarily result in the elimination of racism in US society. In fact, the commitment to this social norm, as Mendelberg (2001, p. 92) admits, is minimal in many cases. ${ }^{9}$ Therefore, this norm of racial equality is compatible with different forms of subtle, and not so subtle, racism, such as the growing colourblindness ideology, which, as noted by Haney-López (2014, p. 87), "bolster dog whistle politics". Colourblindness ideology "[...] laudably envisions an ideal world in which race is no longer relevant to how we perceive or treat each other." (Haney-López, 2014, p. 77). This may seem a desirable ideal in the fight against racial injustice. However, colourblindness makes invisible forms of racial discrimination experienced by racialized people and prevents us from perceiving the privileged status of the non-racialized (Medina, 2012, p. 38). Racist ideologies, whether proudly held or in disguise, are the breeding ground for effective implicit forms of racist communication such as dogwhistle politics. ${ }^{10}$

In the next section, I examine some possible answers to the question of how covert dogwhistles succeed in achieving their goal. In particular, I discuss whether a covert dogwhistle is a specific sort of mechanism of manipulation or whether, on the contrary, it draws on other already familiar linguistic mechanisms such as implicatures or presuppositions.

\section{Implicaturist and Presuppositional Accounts of Covert Dogwhistles}

At first sight, the Gricean model of communication, while successful in explaining conversational exchanges involving cooperation between speakers, does not seem as suitable in accounting for cases of political manipulation through language. This is due, basically, to two constraints. The first, as we have already pointed out, is that the phenomenon of propaganda in general, and dogwhistles in particular, often drives us to go beyond the game of intentions that we usually assume in ideal communication conditions. For instance, covert dogwhistles are effective when they go unnoticed by the target audience. The second has to do with the assumption that speakers and listeners will assume shared conversational goals. Again, covert dogwhistles in particular, and propaganda at large, challenge this assumption. Under normal conditions, the propagandist's desire to manipulate clashes with the listeners' desire to know the truth (see Beaver \& Stanley, 2018; Quaranto \& Stanley, 2021). One could insist, however, that this framework remains promising for clarifying the nature of covert dogwhistles. In what follows, I will block this path and defend that covert dogwhistles cannot be accommodated within either of these two mechanisms. To carry out this

9 As Saul (2017, p. 100) points out, the norm of racial equality is to be understood as a very general one such as "Don't be racist." The norm "Don't be racist" is general enough that each person who follows it can make her own interpretation of what it means so that many people will understand it in a clearly racist way, even if they are not aware of it.

10 After Trump's victory in the USA (Bolsonaro in Brazil, Salvini in Italy, success in favor of Brexit, Vox winning seats in the Spanish Parliament, etc.) racism and sexism (the latter in the form of antifeminism) now enjoy a level of tolerance unacceptable to our democracies. Predictably, the more tolerable racism, sexism, homophobia, etc., become, the less necessary it is to resort to disguised speeches such as dogwhistles. 
task, I compare the features of the phenomena at hand by examining how they behave in the face of plausible deniability, cancellability, calculability and mutual acceptance.

\subsection{Covert Dogwhistles as Semantic Presuppositions or Conventional IMPLICATURES}

When a speaker says something, she communicates information at different levels and not always deliberately. For instance, if she says, "Mr X's sister is a politician, but she is honest," that utterance semantically presupposes that $\mathrm{Mr} \mathrm{X}$ has a sister. Moreover, the speaker is also conveying via (conventional) implicature that there is a contrast between being a politician and being honest (see Grice, 1989/1995). This implicature is triggered because of the conventional meaning of the conjunction 'but'. Thus, semantic presuppositions and conventional implicatures are mechanisms through which a speaker communicates certain information beyond what she has literally said. Implicated or presupposed content is a kind of conventional not-at-issue content (Murray, 2014; Stanley, 2015), i.e., a sort of information that is not "directly challengeable" and that "is directly added to the common ground" (Murray, 2014, p. 2:4). That Mr X has a sister or that there is a contrast between being a politician and being honest are not the issues under consideration; what is under consideration here is whether or not Mr X's sister is a politician as well as an honest person.

According to Stanley (2015, p. 138 ff), a dogwhistle conveys a conventional not-at-issue content. This content is expressive, i.e., its function is not to rule out possible worlds by adding new information to the common ground but to order the available worlds according to a certain order of preferences. Our interest here, however, is not in the ins and outs of Stanley's proposal. What matters for our purposes is to discuss the plausibility of the thesis that dogwhistles are intended to communicate conventionally encoded not-at-issue content via semantic presupposition or conventional implicature. The latter is the option that Stanley (2015) seems to favor.

\subsubsection{The Deniability Argument}

In this subsection, I introduce a version of what Henderson and McCready (2019, pp. 224225) call the deniability argument against those accounts advocating that covert dogwhistles are conventional implicatures or semantic presuppositions. ${ }^{11}$ Let's take Gingrich's ex-

11 The same objection can be found in Khoo (2017, pp. 45-46), although he discusses cancellability rather than plausible deniability. In this paper, however, it is relevant to distinguish cancellability from deniability. I use "cancellability" here for those situations in which, after being confronted, the speaker denies the content suggested by admitting to having suggested it. Note that, so understood, cancellability is like a retraction. I use "deniability", on the other hand, for those situations in which the speaker, after being confronted, denies having suggested what the audience attributes to her (see Mazzarella et al., 2018, p. 16, for a similar use of "deniability"). The distinction is important because, as we will see, it allows us to appreciate a different behavior of conversational implicatures and covert dogwhistles concerning no just deniability but also cancellability. At this point, however, overlooking the difference between the two phenomena has no noticeable consequences since conventional implicatures are neither deniable nor cancellable. 
ample as a paradigmatic case of a covert dogwhistle. Gingrich's speech act, one could argue, suggests something along the lines of "African Americans are lazy" due to the meaning of the phrase "food stamp". A common feature of both semantic presuppositions and conventional implicatures is that they cannot be felicitously denied by the same speaker (Beaver \& Geurts, 2014; Davis, 2019). Let's look at the following conversations:

(1) Dan: Mr X's sister is a politician, but she is honest. (Presupposition: Mr X has a sister)

Dre: I didn't know that Mr X had a sister.

Dan: \#Of course you didn't, he's an only child! (Dan's denial)

(2) Lucy: What about Mr X's sister?

Naia: Mr X's sister is a politician, but she is honest. (Implicature: There is a contrast between being a politician and being honest)

Lucy: I don't think that politicians are dishonest.

Naia: \#I've suggested no such thing (Naia's denial).

As shown in (1) and (2), semantic presuppositions and conventional implicatures are linked to the conventional meaning of the utterances that trigger them in such a way that they cannot be plausibly denied. Covert dogwhistles, on the other hand, are not bound to the conventional meaning of the expressions involved in the speaker's utterance. This is what allows the speaker to plausibly deny the covert appeal, as in (3):

(3) Gingrich: Over here you have a policy which, with Reagan and me as speaker, created millions of jobs-it's called paychecks. Over [ $t$ ] here you have the most successful food stamp president in American history, Barack Obama. (Dogwhistle: African American are lazy)

Journalist: Are you implying that African Americans are lazy?

Gingrich: I don't have anything against African Americans. Why do you think that? (Gingrich's denial)

The veiled nature of covert dogwhistles sharply contrasts with the transparency that their conventional character gives to semantic presuppositions and conventional implicatures. Dan's and Naia's denials clearly fail because of the conventional meaning of their presupposition-triggering and implicature-triggering utterances, while Gingrich's does sound convincing. Plausible deniability is one of the most powerful features of covert dogwhistles, as it allows the dog-whistler to reverse the accusation, for instance, by accusing the opponent of playing the race card.

\subsection{Covert Dogwhistles as Conversational Implicatures}

As we know from Grice (1989/1995), there is another type of implicatures, the so-called conversational implicatures. They are inferences triggered by uttering a sentence and exploiting the Gricean conversational maxims. Unlike conventional ones, conversational implicatures are not determined by the conventional meaning of the expressions involved in the utterances that trigger them. Imagine the following situation. Bea keeps making funny contributions to the conversation. The exchange goes on like this:

(4) Amy: Bea, you're funny!

Bea: I am from Tiflis (Implicature: People from Tiflis are funny). 
Bea's conversational implicature (let's call (b)) does not follow from Bea's assertion (let's call (a)) by virtue of (a)'s conventional meaning. (a) can be uttered in another context without triggering the implicature (b). In other words, (b) follows from (a), in this context, not because of the conventional meaning of the expressions involved in (a), but due to pragmatic reasons. Amy has to infer that what Bea means by (a) is that people from Tiflis are funny so that Bea's utterance is taken as a cooperative contribution to the conversation.

To date, no author has developed a Conversational Implicaturist View of covert dogwhistles. However, Marques (2020, pp. 125-126) has recently raised this possibility. According to such a view, Gingrich's assertion would convey via (conversational) implicature something like the proposition that African Americans are lazy. What sets this proposal apart from the previous one is that the implicatum behaves differently owing to its unconventional nature. In what follows, I argue that conversational implicatures are not successful candidates for explaining covert dogwhistles given how they both behave with respect to plausible deniability, cancellability and calculability, three distinctive features of conversational implicatures. ${ }^{12}$

\subsubsection{The Deniability Argument}

On the surface, covert dogwhistles and conversational implicatures seem to share some central features. A conversational implicature, as noted above, is carried by saying that $p$ not because of the conventional meaning of the utterance that trigger it, but "in virtue of special features of the context" (Grice, 1989/1995, p. 37). Because of this, they seem to be plausibly deniable. Consider (5):

(5) Dev: Where are my slippers?

Ravi: The dog is having a good time in the backyard. (Implicature: The dog is playing with Dev's slippers)

Dev: What? Is the dog playing with my slippers?

Ravi: I didn't say that (Ravi's denial).

Dev: So why did you tell me that the dog is having a good time in the backyard?

Ravi's denial of having implicated that the dog is playing with Dev's slippers is felicitous. It does not contradict the implicature-triggering utterance. Of course, Ravi is not cooperative since his contribution is not an answer to Dev's question, as one might expect. He is infringing the maxim "Be relevant". And yet, Ravi's conversational implicature is plausibly deniable--although the price to be paid by him is to present himself to Dev as being uncooperative. ${ }^{13}$ Ravi's denial in (5), while possible, makes his previous speech act an uncoopera-

${ }^{12}$ In what follows, we will focus specifically on particularized conversational implicatures. Marques (2020) does not specify whether dogwhistles are generalized or particularized conversational implicatures. However, according to the author, covert dogwhistles are conversational implicatures that arise from the observation of the maxim of relevance and, as Levinson (1983, p. 127) points out, "all the implicatures that arise from observing the maxim of Relevance are particularized, since utterances are relevant only with respect to the particular topic or issue at hand".

13 Whenever the implicature is particularized and results from the observation of the maxim of relevance, the speaker's denial turns her contribution into an uncooperative one, as the implicature is what makes the speaker's contribution relevant to the conversation. 
tive contribution to the conversation. Gingrich's denial in (3), however, is not perceived as a violation of any conversational maxim, and his assertion remains a cooperative contribution even after denial. The difference in how the speaker is perceived by the audience when she denies having implicated anything and denies having dogwhistled anything is a prima facie reliable predictor for distinguishing conversational implicatures from covert dogwhistles. Still, it could be argued that this disparity is not substantial enough to make the case that covert dogwhistles are not conversational implicatures.

\subsubsection{The Cancellability Argument}

As we have seen above, another feature of conversational implicatures that set them apart from covert dogwhistles is their cancellability (see e.g., Grice, 1989/1995, p. 39; Potts, 2015, pp. 183-184). ${ }^{14}$ Cancellability, as opposed to deniability, involves the speaker admitting that the audience would be right in attributing to her the content she has actually communicated if she had not cancelled it. Consider the following dialogues, the former being a case of cancellation of a conversational implicature and the latter, a case of cancellation of covert dogwhistle:

(6) Ann: Sam does not like to work.

Tom: Well, she is African American. (Implicature: African Americans are lazy.)

Ann: What are you suggesting?

Tom: I heard myself, my bad. I didn't mean to imply that African Americans are lazy. (Tom's cancellation.)

(7) Tom: Over here you have a policy which, with Reagan and me as speaker, created millions of jobs-it's called paychecks. Over there you have the most successful food stamp president in American history, Barack Obama. (Dogwhistle: African Americans are lazy.)

Ann: What are you suggesting?

Tom: \# I heard myself, my bad. I didn't mean to imply that African Americans are lazy. (Tom's cancellation.)

Note that Tom's cancellation in (6) is felicitous, even though one may well doubt his sincerity. The crux of the matter, though, is that when Tom cancelled what he had implicated, he made explicit a piece of implicit information that Ann had already inferred, and that Tom presumed that she would infer. Hence, cancellation only makes sense based on the speaker's presumption of the recognition of the implicated content by the audience. If the speaker did not presume the audience's recognition of the implicatum, there would be no reason to cancel it. However, this is precisely why the cancellation of a covert dogwhistle is not feasible, as shown in (7). Cancelling a covert dogwhistle involves revealing a strategy of manipulation whose effectiveness lies in concealing it from the target audience. Conversational implicatures, unlike covert dogwhistles, work upon the basis of the mutual recognition of intentions by the participants of the conversation. Conversational implicatures are successful when the listeners recognize them, and their cancellation does not involve revealing any new information to the listeners.

\footnotetext{
${ }^{14}$ I am here considering only explicit cancelability.
} 
One might insist, however, that (7) is underdeveloped and argue that the content conveyed by the covert dogwhistle does take the form of a conversational implicature. It could be argued that Tom is suggesting that the Republicans' economic policies are better than the Democrats'. While the policies adopted by the Republicans have served to "create millions of jobs," the policies approved by the Democrats not only do not create jobs, but also discourage people from seeking them. The speaker, thus, implicates that there is a close connection between being a food stamp recipient and laziness. However, by calling Obama "the most successful food stamp president," Tom is going beyond that: he is exploiting some stereotypes triggering an association in the audience between being African American and being lazy, as many people publicly reported. Now, can it be argued that Tom is suggesting that there is something wrong with being a food stamp recipient, and also particularly targeting African Americans?

Marques (2020, p. 125) appeals to the maxim of relevance to explain how covert dogwhistles work and why they are conversational implicatures. Appealing to this maxim, however, does not allow us to account for Tom's dogwhistle because cancelling the alleged dogwhistled content conveyed by the phrase "food stamp" does not render the speaker's contribution irrelevant, as would be the case if the speaker were to cancel his implicature that there is something wrong with being a food stamp recipient. However, Tom's puzzling cancellation in (7) may be due to something else. The successful cancellation of a conversational implicature sometimes depends on how determinable the set of implicatures compatible with the implicature-triggering utterance is. This is due to a feature that conversational implicatures sometimes have: indeterminability. As Levinson points out, sometimes an expression can give rise to different implicatures and it is not always possible to determine exactly which set of implicatures is compatible with that expression (see Levinson, 1983, pp. 117-118). It could be argued, then, that perhaps Gingrich's cancellation is infelicitous because the content cancelled does not correspond to the suggested content that most listeners have identified. However, the set of implicatures compatible with an implicature-triggering expression is not infinite. Only a certain number of implicatures are reasonably compatible with what the speaker has said. Thus, Gingrich may have meant to suggest that Obama's policies are harmful to the whole country or food stamp recipients insofar as they encourage them not to work, he may have suggested that food stamp recipients are victims of a harmful economic policy, that they selfishly take advantage of a detrimentally generous system or that they are lazy. But there does not seem to be any linguistic element that together with the context would lead the audience to infer that anything negative is being suggested about African Americans in particular. Thus, Gingrich's racial appeal has to do its job differently.

\subsubsection{The Calculability Argument}

Conversational implicatures and covert dogwhistles also differ in their behavior concerning calculability. As noted above, conversational implicatures are calculable. As Grice points out, calculation is a process carried out by the audience to preserve the assumption that the speaker is observing the Cooperation Principle (Grice, 1989/1995, pp. 39-40). For the audience to calculate an implicature that $p$ from what is said, they must be aware that the speaker conveyed $p$ in the first place. The speaker, thus, has to try to be as transparent as possible so that the audience can infer $p$. Covert dogwhistles, however, are not calcula- 
ble. On the one hand, it is not necessary for the oblivious audience to infer a dogwhistle from the conventional meaning of the expressions involved and the conversational maxims to preserve the assumption of cooperation (see Levinson, 1983, p. 117). On the other hand, the speaker does not seek transparency to make it easier for the oblivious audience to work out his dogwhistle. Only when the covert dogwhistle has been identified can the steps leading from the main speech act to the dogwhistle be traced. But having the oblivious audience spot the dogwhistle is a sign that in some way, the speaker's strategy of concealment has failed. Thus, while a conversational implicature is successful when the audience recognizes the speaker's intentions and can work out it, the success of a covert dogwhistle lies precisely in the fact that the oblivious audience is neither able to recognize the speaker's intentions nor to calculate the dogwhistle.

\subsection{Covert Dogwhistles as Pragmatic Presuppositions}

As well as semantic presupposition, there is another type of presupposition, so-called pragmatic or speaker presupposition (see, e.g., Stalnaker, 1974, 2014; Schwarz, 1977; Beaver \& Geurts, 2014). According to this pragmatic understanding of presuppositions, and roughly speaking, "P pragmatically presupposes $\mathrm{Q}$ iff whenever the utterance of $\mathrm{P}$ is conversationally acceptable, the speaker of $\mathrm{P}$ assumes $\mathrm{Q}$ and believes his audience to assume $\mathrm{Q}$ as well." (Schwarz, 1977, p. 247) The emphasis in this definition of presupposition is on the speaker rather than on the linguistic meaning of the expressions involved in an utterance. Thus, pragmatic presuppositions point to a broader phenomenon than semantic presuppositions. The former include all sorts of assumptions by conversational participants such as that the speaker knows the listener, or that the listener understands the speaker's language, and so on. So, pragmatic presuppositions are not necessarily bound up with the meaning of certain expressions. In what follows, I focus on those pragmatic presuppositions that cannot be explained as semantic ones.

\subsubsection{Mutual Acceptance argument}

A covert dogwhistle cannot be a pragmatic presupposition. The pragmatically presupposed content, whether it is part of the common ground or becomes part of it by accommodation, requires the audience's acceptance to be successful, which would make it overt. This is so regardless of whether the content of the dogwhistle is common ground or not. Two scenarios can be envisaged in which pragmatic presuppositions prove to be unsuitable to account for covert dogwhistles: one in which the presupposition is already shared by all participants in the conversation, and a second in which the presupposition is not initially shared but is accommodated by the audience.

- Scenario 1: The speaker's presupposition could already be part of the common ground. ${ }^{15}$ Gingrich could pragmatically presuppose that at least part of his audience

15 Stalnaker (2014, p. 25) characterizes the common ground as "what is presumed to be common knowledge among the participants in a conversation", which has an iterative structure: "a proposition is common ground between you and me if we both accept it (for the purposes of the conversation), we both accept that we both accept it, we both accept that we both accept that we both accept it, and so on". 
presupposes that the expression "food stamp" refers to African Americans, and that they are lazy. These two presuppositions may lead Gingrich to use the phrase "food stamp president". But if that were the case, that audience would recognize that the phrase "food stamp" is one of their words, i.e., an expression that has, in addition to a conventional meaning readily accessible to all listeners, a non-standard meaning that can only be decoded by members of their in-group. So, the reason why a covert dogwhistle cannot be a kind of pragmatic presupposition is that in case the participants in the conversation took those presuppositions for granted, the presupposed information would already be common knowledge and, the dogwhistle would not be covert, but overt.

- Scenario 2: The audience does not take for granted the speaker's presupposition but, by hearing the speaker's utterance, they add the presupposition to the common ground via accommodation (see, e.g., Karttunen, 1974; Stalnaker, 1974, 2014; Lewis, 1979). If one takes accommodation as a process consciously carried out by the audience, as "the result of rational responses to events that take place in the course of a conversation" (Stalnaker, 2014, p. 6), then the dogwhistle would no longer be covert but overt, as would be the case if the presupposition was already part of the common ground.

\section{Two Simple Views}

\subsection{Covert Dogwhistles as Inference-triggers}

Both Conventional Implicaturist and Semantic Presuppositional accounts characterize dogwhistles as code words. As we have seen, according to these views, covert dogwhistles are expressions that encode, by implicating or presupposing, a piece of content that is available only to a part of the audience. Khoo (2017) puts forward his Inference-driven Account, as opposed to this thesis. He argues that dogwhistles do not code anything. Dogwhistles are not expressions with a concealed or implicit semantically coded meaning. Instead, they are expressions that enable the audience to infer some harmful contents. According to Khoo (2017, p. 35) "code words don't work by being vehicles of implicit communication; they work by triggering inferences which they are not used to communicate." At first glance, Khoo's proposal closely resembles the Conversational Implicaturist or the Pragmatic Presuppositional accounts: hearers infer something from what the speaker has said, which is not part of the conventional meaning of the words involved. However, Khoo's proposal has the advantage of not requiring dogwhistles to have the hallmarks of either conversational implicatures or pragmatic presuppositions, thus eluding the objections raised to views that appeal to them. This proposal can be schematically depicted as follows:

- Explicit Statement: $\mathrm{x}$ is C.

- Existing Belief: If something is $\mathrm{C}$, then it is $\mathrm{R}$.

- Inferred: $x$ is $\mathrm{R}$.

Suppose that Explicit Statement is Gingrich's utterance "Obama is the most successful food stamp president of the American history", and Existing Belief is "Only lazy African Amer- 
icans use food stamps". Then, Inferred would be something like "Obama is the most successful president for the lazy African Americans in American history". Thus, the phrase "food stamp" in Gingrich's Explicit Statement provides the necessary semantically non-racial information so that, given a racial belief (prejudice) already held by part of the audience, those prejudiced hearers could draw a racist conclusion. Hence, dogwhistles are not code words, but inference-triggers. They are not code words, but they do have coded effects (Khoo, 2017, p. 49).

Although Khoo does not take into account Saul's distinction between overt and covert dogwhistles, his proposal is consistent with it. He argues that the speaker's utterance can have the above-described effect upon a part of the audience without being intended by the speaker and, more importantly, the audience can infer the discriminatory content unconsciously (Khoo, 2017, p. 50). However, despite the virtues of this proposal, it faces two problems. First, as Khoo admits, his proposal has to deal with the problem of why two co-extensional expressions, $\mathrm{A}$ and $\mathrm{B}$, contrary to what his proposal would imply, do not trigger the same inference. For example, while the phrase "inner city" raises racial prejudice in part of the audience, an extensionally equivalent expression such as "densely populated, highcrime, urban areas" does not (Khoo, 2017, p. 50). Second, to my mind, Khoo has to struggle with explaining how one who holds an explicitly racist belief, as his theory must assume to explain how she infers the dogwhistle, can change her attitude (her voting intention, for example) upon discovering that the dog-whistler's speech act was racist.

\subsection{Covert Dogwhistles as Attitude-Foregrounders}

As we have seen, according to Saul (2018), the function of a covert dogwhistle is to raise the (racist) audience's pre-existing attitudes to salience. Bringing the (racist) audience attitudes to the fore is sufficient for some subsequent actions of the audience to be partly driven by their exposure to the covert dogwhistle, without the audience having to make any extra inferences. ${ }^{16}$ As I see things, the attitudes raised to salience can be both cognitive (prejudices, stereotypes) and non-cognitive such as emotions (e.g., anger, resentment or disgust) or implicit attitudes. This would better explain why, like Horton's case shows, the attitudes of oblivious audience can change again once the racist nature of the dog-whistler's speech act becomes exposed. Only in a public that repudiates overt forms of racism, but still harbors implicit racist attitudes (or explicit attitudes that they do not identify as racist), can a change of attitude be brought about. ${ }^{17}$ As Cappelen and Dever (2019) have recently noted, dogwhistles have (what they call) non-cognitive lexical effects, that is, non-propositional effects (see also Saul, 2018, p. 377). Dogwhistles "trigger pictures, memories, affect your mood, your motivation, and can change 'the way you think about something,' rather than the content of what you think" (Cappelen \& Dever, 2019, p. 119). So, rather than inference-triggers, covert dogwhistles are attitude-foregrounders. As I argue elsewhere (Torices, 2019, p. 152), the dog-whistler manages to raise audience attitudes to sali-

16 For Saul (2018, p. 377) covert dogwhistles are covert perloculionary speech acts.

17 The results of test-retest reliabilities for discriminatory implicit attitudes are not always acceptable $(\mathrm{r}=.5$ with the minimum acceptable score being $\mathrm{r}=.8)$, even though some improvements in measuring the reliability of the IAT seem to yield more promising results (see e.g., Greenwald et al., 2019, p. 17). 
ence via associations. As Toribio points out, associations result from "reliable, reinforcing connections, as they are typically learnt by exposure" (Toribio, 2018, p. 42). Unlike inferential transitions, associative transitions are not made based on the content of the associated items. They are acquired "mainly through conditioning and reinforcement" (Toribio, 2018 , p. 44). For instance, through the systematic co-occurrence of a linguistic expression, image or symbol with a stereotypical image or with clearly negative linguistic expressions.

A proposal like the one suggested here has several advantages. Firstly, as the inference-triggers account, it gets around the problems of the theories discussed in section 4 . Covert dogwhistles are plausibly deniable, are not cancellable nor calculable. Plausible deniability, cancelability and calculability apply to contents, not to the effects of those contents. Moreover, since the burden of their effectiveness falls on the listeners, this proposal can illustrate why the accusation, to the mindful audience, of hearing something that was unsaid is compelling for a part of the electorate. The charge that racism is in the listener's head and not in the speaker's words is quite common when someone is blamed for playing the race card, and then a struggle for credibility between the mindful audience and the dog-whistler begins. These advantages are not exclusive to the attitude-foregrounders approach, but also extend to Khoo's inferentialist account. However, the attitude-foregrounders approach can provide a simple answer to the first of the two problems facing Khoo's proposal. Two expressions, $\mathrm{A}$ and $\mathrm{B}$, can be co-extensional and yet rise to salience different attitudes because A, for instance, but not B, appears systematically in connection with a stereotypical image, etc. Unlike Khoo's proposal, in the attitude-foregrounders approach it is not what $\mathrm{C}$ stands for in the speaker's utterance " $\mathrm{x}$ is C", but the very expression $\mathrm{C}$, which does the work. The attitude-foregrounders view can also provide an answer to the second problem. Many people may harbor racist non-cognitive attitudes despite having explicit anti-racist beliefs. Covert dogwhistles can take advantage of such non-cognitive attitudes, for instance, racial resentment. When it becomes clear that a speech act serves to raise to salience racist attitudes, explicit anti-racist beliefs can do the job of neutralizing the influence of racist non-cognitive attitudes.

Finally, I would like to raise one possible objection to both proposals. Someone might reasonably argue that these proposals that assume that dogwhistles exploit the pre-existing attitudes of part of the audience cannot account for how a dogwhistle works in cases where its purpose is to elicit new negative attitudes (beliefs, stereotypes, emotions, biases...) in the audience on groups towards which that audience has not yet acquired a negative attitude. As of yet, however, there does not seem to be evidence to support this view. Covert dogwhistles are not intended to make people racist, there are other mechanisms for that. The purpose of a covert dogwhistle is to take advantage of the explicit or implicit racism of part of the electorate. According to Saul's analysis of the Horton ad, drawing on Mendelberg (2001), "while levels of racial resentment were unaffected by viewing the ad, the relationship between racial resentment and voting intentions was strongly influenced by it." (Saul, 2018 , p. 366). In other words, people did not become more racist after viewing the ad, what the ad succeeded in doing was to make that racism influence their behavior without many of them realizing it. This seems to suggest that the function of a dogwhistle, as Saul points out, is to bring certain pre-existing attitudes to bear, rather than to produce certain new attitudes in the audience. 


\section{Conclusion}

In this paper, I have argued that covert dogwhistles are neither implicatures nor presuppositions. Unlike conventional implicatures and semantic presuppositions, covert dogwhistles are plausibly deniable. Being plausibly deniable is a feature partially shared with conversational implicatures. However, while both conversational implicatures and cover dogwhistles are plausibly deniable, the speaker's denial of the former, but not of the latter, makes the speaker appear to the audience as uncooperative. Furthermore, conversational implicatures are cancellable and calculable, while covert dogwhistles are not. Finally, unlike covert dogwhistles, pragmatic presuppositions require the speaker and listener mutual acceptance of its content to be successful.

I concluded this paper by outlining two simple theories for covert dogwhistles according to which covert dogwhistles are not code-words, but they have coded effects. According to the first one, defended by Khoo (2017), covert dogwhistles are inference-triggers. According to the second one, with which I sympathize in line with Saul (2018), they are attitude-foregrounders. As I have tried to show, the attitude-foregrounders view can solve some of the problems that Khoo's theory has to deal with. The attitude-foregrounders view, therefore, provides, to my mind, the most promising starting point for accounting for covert dogwhistles.

\section{Acknowledgements}

I am deeply grateful to Jennifer Saul and Neftalí Villanueva for their comments and suggestions while supervising earlier versions of this paper. I would also like to thank all the people who have contributed to improve the ideas defended here: Manuel Almagro, Alex Davies, María José Frápolli, Dan López de Sa, Teresa Marques, Eduardo Pérez-Navarro, Manuel de Pinedo, Andrés Soria, and two anonymous reviewers for Theoria. This paper has been funded by the Spanish Ministry of Science, Innovation and Universities under the grant FPI/BeS-2014-067584 and the research project PID2019-109764RB-I00, by the Regional Government of Andalusia under the research projects B-HUM-459-UGR18 and P18 FR-2907, and by the University of Granada under a "Contrato Puente" fellowship and the excellence unit FiloLab-UGR UCE.PPP2017.04.

\section{REFERENCES}

Albertson, B. (2015). Dog-Whistle Politics: Multivocal Communication and Religious Appeals. Political Behavior, 37(1), 3-26.

Beaver, D. \& Geurts, B. (2014). “Presupposition.” In Edward N. Zalta (Ed.). The Stanford Encyclopedia of Philosophy. URL = https://plato.stanford.edu/archives/win2014/entries/presupposition/

Beaver, D. \& Stanley, J. (2018). Toward a Non-Ideal Philosophy of Language. Graduate Faculty Philosophy Journal, 39(2), 503-547.

Cappelen, H. \& Dever, J. (2019). Bad Language. Oxford: Oxford University Press.

Davis, W. (2019). “Implicature.” In Edward N. Zalta (Ed.). The Stanford Encyclopedia of Philosophy. URL = https://plato.stanford.edu/archives/fall2019/entries/implicature/ 
Elliott, D. (2012, January 17). 'Food stamp president': Race code, or just politics. NPR. Retrieved from https://www.npr.org/2012/01/17/145312069/newts-food-stamp-president-racial-or-just-politics

Ellul, J. (1965). Propaganda: The Formation of Men's attitudes. New York: Random House.

Gilens, M. (1996). 'Race coding' and white opposition to welfare. The American Political Science Review, 90(3), 593-604.

Greenwald, A. G., Brendl, M., Cai, H., Charlesworth, T., Cvencek, D., Dovidio. J. F., Friese, M., Hahn, A., Hehman, E., Hofmann, W., Hughes, S., Hussey, I., Jordan, C., Jost, J., Kirby, T., Lai, C. K., Lang, J., Lindgren, K. P., Maison, D., Ostafin, B. D., Rae, J. R., Ratliff, K., Smith, C. T., Spruyt, A., \& Wiers, R. W. (2019). The Implicit Association Test at age 20: What is known and what is not known about implicit bias. https://doi.org/10.31234/osf.io/bf97c Retrieved from https://psyarxiv.com/bf97c

Grice, P. (1989/1995). Studies in the Way of Words. Cambridge: Harvard University Press.

Haney-López, I. (2014). Dog Whistle Politics: How Coded Racial Appeals Have Wrecked the Middle Class. New York: Oxford University Press.

Henderson, R., \& McCready, E. (2019). Dogwhistles and the At-Issue/Non-At-Issue Distinction. In D. Gutzmann \& K. Turgay (Eds.). Secondary Content (pp. 222-245). Leiden: Brill.

Henderson, R. \& McCready, E. (2020). Dogwhistles, trust and ideology. Proceedings of the $22^{\text {nd }}$ Amsterdam Colloquium, 152-160.

Hurwitz, J. \& Peffley, M. (2005). Playing the Race Card in the Post-Willie Horton Era: The Impact of Racialized Code Words on Support for Punitive Crime Policy. Public Opinion Quarterly, 69(1), 99-112.

Karttunen, L. (1974). Presuppositions and Linguistic Context. Theoretical Linguistics, 1, 181-194.

Khoo, J. (2017). Code Words in Political Discourse. Philosophical Topics, 45(2), 33-64.

Levinson, S. C. (1983). Pragmatics. Cambridge: Cambridge University Press.

Lewis, D. (1979). Scorekeeping in a language game. Journal of Philosophical Logic, 8, 339-359.

Marques, T. (2020). How can philosophy of language help us navigate the political news cycle? In E. Vintiadis (Ed.). Philosophy by Women: 22 Philosophers Reflect on Philosophy and Its Value (pp. 122-130). New York: Routledge.

Mazzarella, D., Reinecke, R., Noveck, I., \& Mercier, H. (2018). Saying, presupposing and implicating: How pragmatics modulates commitment. Journal of Pragmatics, 133, 15-27.

Medina, J. (2012). The Epistemology of Resistance: Gender and Racial Oppression, Epistemic Injustice, and Resistant Imaginations. Oxford: Oxford University Press.

Medina, J. (2018). Resisting Racist Propaganda: Distorted Visual Communication and Epistemic Activism. Southern Journal of Philosophy, 56(S1), 50-75.

Mendelberg, T. (2001). The Race Card: Campaign Strategy, Implicit Messages, and the Norm of Equality. Princeton: Princeton University Press.

Murray, S. (2014). Varieties of Update. Semantics and Pragmatics, 7, (2), 1-53.

Nisbet, M. (2012, January 18). Food Stamp President? The Science of Why Gingrich's Race-Tinged Label Sticks. Big Think. Retrieved from https://bigthink.com/age-of-engagement/food-stamp-president-thescience-of-why-gingrichs-race-tinged-label-sticks.

Potts, C. (2015). Presupposition and Implicature. In S. Lappin \& C. Fox (Eds.). The Handbook of Contemporary Semantic Theory (pp. 168-202). Oxford: Willey-Blackwell.

Quadagno, A. \& Stanley, J. (2021). Propaganda. In J. Khoo \& R. K. Sterken (Eds.). The Routledge Handbook of Social and Political Philosophy of Language (pp. 125-146). New York: Routledge.

Saul, J. (2017). Racial Figleaves, the Shifting Boundaries of the Permissible, and the Rise of Donald Trump. Philosophical Topics, 45(2), 97-116.

Saul, J. (2018). Dogwhistles, Political Manipulation and Philosophy of Language. In D. Fogal, D. Harris \& M. Moss (Eds.). New Works on Speech Acts (pp. 360-383). New York: Oxford University Press.

Schwarz, D. (1977). On pragmatic presupposition. Linguistics and Philosophy, 1(2), 247-257.

Sonmez, F. (2012, January 22). Newt Gingrich has created a food stamp kind,' Clyburn says. Retrieved from https://www.washingtonpost.com/blogs/election-2012/post/newt-gingrich-has-created-a-food-stampking-clyburn-says/2012/01/22/gIQAQT2sIQ_blog.html 
Stalnaker, R. (1974). Pragmatic presuppositions. In M. K. Munitz, \& P. K. Unger (Eds.). Semantics and Philosophy (pp. 197-2014). New York: New York University Press.

Stalnaker, R. (2014). Context. Oxford: Oxford University Press.

Stanley, J. (2015). How Propaganda Works. Princeton: Princeton University Press.

Toribio, J. (2018). Implicit Bias: From Social Structure to Representational Format. Theoria: An International Journal for Theory, History and Foundations of Science, 33(1), 41-60.

Torices, J. R. (2019). Ranking the world through words: disagreement, dogwhistles, and expressivism. (Doctoral Dissertation). Universidad de Granada. [http://hdl.handle.net/10481/56428]

Valentino, N., Hutchings, V. \& White, I. (2002). Cues that Matter: How Political Ads Prime Racial Attitudes During Campaigns. The American Political Science Review, 96(1), 75-90.

Witten, K. (2014). Dogwhistle Politics: The New Pitch of an Old Narrative. Unpublished Manuscript.

José Ramón Torices belongs to the excellence unit FiloLab-UGR and the research group Filosofía y Análisis (HUM-975). His areas of interest are the philosophy of language and epistemology. He got his PhD at the University of Granada (2019) and has been visiting researcher at the University of Edinburgh (2017) and the University of Sheffield (2018).

Address: Departamento de Filosofía I, Facultad de Psicología, Universidad de Granada, Campus Universitario de Cartuja, s/n, 18011, Granada, Spain. Email: jrtorices@gmail.com

ORCID: 0000-0003-4078-1262 